\title{
EMPREGABILIDADE, OCUPAÇÃO E NOVAS FORMAS DE TRABALHO"
}

\author{
Nelson Mannich ${ }^{*}$
}

\begin{abstract}
Resumo:
Novas tecnologias da comunicação e informação lèm reflexos nas relações de trabalho. onde empregabilidade e ocupação apresentam-se com novos desafios. No lugar do tradicional trabalho subordinado do empregado com registro e inclusão social, surgem novas formas de trabalho, em especial o teletrabalho e o que se passou a denominar parassubordinação. Algumas reformas são impostas de forma unilateral. Com intuito de reduzir custos, assistimos a contratação irregular de empregados por meio de cooperativas fraudulentas ou terceirização selvagem, com desprezo a direitos fundamentais. É imperiosa a reforma das relaçñes trabalhistas. sob a ótica do trabalho comc: valor e, do ser humano como medida dos valores.

Palavras-chave: I:mpregabilidade. Ocupação. Flexibilização. Terceirização. Trabalho avulso. Cooperativa de mão-de-obra. Parassubordinação.
\end{abstract}

\begin{abstract}
:
New communication and information technologies interfere labor relationships. where empregability and occupation have been challenged. Instead of traditional. subordinated labor, with registered and social inserted workers, new types of labor arise, specially telework, called parasubordiation. Some reforms has been imposed unilaterally. In order to reduce costs, we watch irregular hiring of workers by fraudulent cooperatives, that act in basic terceiriziation and disicgard of civil rights. It is mandatory the ruform of labor relations, putting labor as value. and the human being as the measure of values.
\end{abstract}

Keywords: Empregability. Occupation. Flexibilization. Terceirization. Piecework. Labor Cooperatives. Parasubordination.

Crianos "época da velocidade, mas nos sentimos enclausurados dela.

A máquina, que produz abundîncia. tem-nos deixado $: m$ penivia.

Nossos conhecimentos fizeram-nos céticos: nossa inteligência, empedernidos e cruéis.

Pensamos em demasia e sentimos pouco.

Mais do que máquinas. precisamos de hrmanidade.

Mais do que inteligência, precisamos de afeição e doçura.

Sem estas virtudes, a vida seria de violência e tudo será perdido.

(Charles ('haplin, 1889-1977.)

\footnotetext{
1 Congresso Mundial de Administradores-Gramado. 11/6/04.

- Professor Titular e vice-chefe do Departamento de Direito do Trabalho da Faculdade de Direito da Universidade de Sào Paulo. Professor Titular de Direito do Trabalho da Faculdade de Dircito da Universidade Mackenzic.
} 
Introdução

O desemprego é uma das faces visíveis da crise e das mudanças no mundo do trabalho. Já contabilizamos mais de 4 milhões de desempregados e 35 milhões no mercado informal' e tudo indicá o agravamento desse quadro, apesar de recente declínio do desemprego.

Refletir sobre empregabilidade, ocupação e novas formas de trabalho implica buscar possíveis respostas, para as quais não há consenso entre os juristas, mesmo porque envolve outras diversas áreas, como Economia e Administração.

Embora o Direito do Trabalho. por situar-se na confluência do econômico com o social. seja mais sensível a essas questões, não pode ignorar os demais aspectos envolvidos, em especial os econômicos. De qualquer forma. há o desafio de conciliar a adaptação exigida por tais imperativos aos princípios do Direito do Trabalho. Ou seja, no ajuste das normas jurídicas à realidade econômica, como estabelecer limites possíveis ou necessários e determinar yuais são.

Para enfrentar o tema, devc-se analisar, ainda que superficialmente, o que se entende por empregabilidade c ocupação, para serem projetadas as novas formas de trabalho.

\section{Empregabilidade e ocupaçâo}

\section{I.1. Empregabilidade}

Empregabilidade corresponde à aptidão de ser empregável, ${ }^{2}$ ou seja, de obter emprego ou trabalho. nele permanecer e progredir, levando-se em conta exigências do mercadu de trabalho, como conhecimentos, habilidades e comportamentos. ${ }^{3}$ Portanto,

PASTORE, José. A agonia do emprego. São Paulo: LTr, 1997. p. 22.

Do inglês "employability"

Conf. MINARELLI, Josẻ Augusto. Empregahilidade - como ter trabalho e remuneração sempre, 24. ed. São Paulo: Gente, 1995. p.ll e CARVALHO, Pedro Carlos de. Empregabilidade. A competência necessária para o sucesso no novo milênio. Campinas: Alínea, 2004. p. 49. Conf., ainda, KON, Anita; BANKO. Catalina; MELCHER, Dorothea; CACCIAMALI, Maria Cristina. (Coord.). Costos Sociales de lãs Reformas Neoliberales em América Latina. Caracas: Miguel Angel Garcia, 2000. JANUZZI, Paulo de Martino. Indicadores Sociais no Brasil. Conceitos, fontes de dados e aplicaçōes. 2. ed. Campinas: Alínea, 2003. AZEREDO, Beatriz. Politicas Píblicas de Emprego. São Paulo: ABET - Associação Brasileira de Estudos do Trabalho, 1998.CHAAD. José Paulo Zeetano; PICCHETTI. Paulo. (Orgs.). Mercado de Trabalho no Brasil. Padrões de comportamento e transformações institucionais. São Paulo: LTr. 2003. OIT - Oficina Intermacional Del Trabajo. Panorama Laboral. Lima. 2003. In: WAJNMAN, Simone; MACHADO. Ana Flávia. (Orgs.). Mercado de Trabalho. Uma análise a partir das pesquisas domiciliares no Brasil. Belo Horizonte: UFMG, 2003. VIGORITA, Luciano Spagnuolo; CARINCI, Maria Teresa. (Orgs.). Quale futuro per il Dirito del Lavoro? La política del Governo: dal libro bianco al disegno di legge delega sul mercato del 
empregabilidade relaciona-se com habilidades para manter-se no emprego ou conseguir um emprego ou trabalho, ou com o conjunto de exigências para contratar alguém.

Empregabilidade tem a ver com qualificação profissional e permanente atualização, responsabilidade essa mais do Estado que das empresas, no âmbito das políticas públicas. É muito comum atribuir a culpa do desemprego de alguém à sua falta de empregabilidade. No entanto, avança a noção segundo a qual cabe ao Estado preparar o trabalhador. levando em conta as necessidades do mercado de trabalho e suas constantes alterações. De acordo com essa noção, não cabe ao Estado apenas assegurar empregos. mas tornar o trabalhador apto a ser contratado, excrcendo, nesse ponto, importante $e$ limitado papel de contur o avanço do desemprego. ${ }^{4}$

Devemos utilizar a cxpressão mercado de Irabalho com reservas, pois não sc admitc que o mercado substitua o Estado na tarefa de fixar determinadas garantias fundamentais. Se, como sabido, o mercado só funciona à base de limitações, cabe ao Direito do Trabalho integrar as regras que organizam o mercado como um todo, mediante princípios e sanções. ${ }^{5}$ Há queixas de excesso de regras, impondo-se maior flexibilidade. daí a referência a patamares mínimos. Além disso, sendo distante o ideal do pleno emprego. combate-se toda forma de trabalho infantil ou capaz de reduzir o trabalhador à condição análoga a de escravo, colocando-se o trabalho decente como protótipo de qualquer atividade humana.

De qualquer forma, como há inúmeros critérios relacionados a empregabilidade, utilizaremos o texto elaborado pelo Departamento de Educação do Estado de Michigan (Anexo [J) ${ }^{6}$ apenas para exemplificar.

De acordo com o texto, destinado a discutir o curriculo escolar daquele estado americano. no que se refere a empregabilidade, foram identificadas dez habilidades relacionadas ao conceito de empregabilidade. que deveriam ser desenvolvidas durante o processo de formação, possibilitando aos alunos boa colocação no mercado de trabalho e perspectivas de se desenvolverem como profissionais.

lavoro. Atti della gionata di studio. Milão: DOTT. A. Giuffrè Ed, 2002. POCHAMANN, Márcio. $O$ emprego na globalização. A nova divisão internacional do trabalho e os caminhos que o Brasil escolheu. São Paulo: Boitempo, 2001. POCHAMANN, Márcio. (Org.) Reestruturação prodhutva. Perspectivas de desenvolvimento local com inclusão social. Petrópolis. Vozes, 2004. MANNRICH. Nelson. Modernização do contrato de trabalho. São Paulo: LTr, 1998.

POCHMANN, Marcio. O emprego na globalização. São Paulo: Boitempo. 2001. p. 51.

Gerard Lyon-Caen.

Trata-se de material gentilmente cedido pelo professor Hèlio Zylberstajn, da FEA/USP. 


\subsection{Ocupação}

Por sua vez, o termo ocupação tem a ver com cargo. Não é nosso objetivo explorar essa questão, apenas fazer referência à evolução registrada, se é que ocorreu. Para melhor se entender esse tema, deve-se analisar, por exemplo, "a proporção de cada grupo ocupacional nu estrutura lo emprego" (Hélio Zylberstajn).

A partir da constatação do aumento do emprego no setor de serviços e conseqüente diminuição no setor da indústria, passou-se a refletir sobre a formação dos trabalhadores na sociedade pós-industrial e conseqüente evolução da estrutura do emprego. ${ }^{7}$ Em conseqüência, deu-se prioridade à formação de um novo trabalhador, levando-se em conta os novos cenários, com ênfase na qualificação profissional e respectivas habilidades exigidas pelo novo mercado de trabalho.

De fato, estão ocorrendo mudanças, mas não tão drásticas como as alardeadas, como se infere da análise dos gráficos apresentados no Anexo I, com dois quadros. De acordo com o quadro I, observa-se pequena variação no setor da indústria, com incremento da ocupação no setor de serviços. No quadro 2, há aumento da escolaridade o que comprova que empregabilidade tem a ver com formação. De qualquer forma, não basta mais apenas saber ler e escrever, sem dominio das novas țcnologias de comunicação e informação. Dai a relação entre empregabilidade e maior escolaridade, especialmente quando mais voltada à capacitação tecnológica.

Constata-se o fim do emprego tradicional, com estabilidade, tempo integral e contrato de prazo indeterminado. Nossa experiência de emprego vinculava-se, no âmbito jurídico, ao sistema protecionista da sociedade industrial. Do ponto de vista econômico. levando-se em conta o sentido de ocupação. emprego corresponde a "trabalho remunerado" 8 Tal conceito deve avançar para incluir outras formas de trabalho, com possibilidades de obtenção de renda e não apenas salário.

\subsection{Respostas aos desafios}

Nota-se resposta ambígua por parte das empresas a tantos desafios. De um lado, fala-se de "gestão de pessoas" ou "gestão do conhecimento" eximindo-se, assim, de sua função social, inclusive no tocante a empregabilidade; de outro, em face da competição e pressionadas a reduzir custos, algumas introduziram reformas unilaterais nas relações de emprego, deixando sistematicamente de cumprir a legislação tida por obsoleta,

Id.. p. 52.

Arman Percira. 
ou simplesmente implantando o que se pode denominar "terceirização selvagem" com o comprometimento das condições de trabalho e rebaixamento dos salários, com perda dos chamados direitos históricos do trabalhador.

\section{Novas formas de trabalho}

Não se confundem novas formas de trabalho com novas modalidades de contratação do trabalhador. No entanto, na prática, novas modalidades de contratação, por fugirem dos padrões clássicos de proteção, podem corresponder a novas formas de trabalho, daí a razão de as abordamos.

$\mathrm{Na}$ verdade, novas modalidades de trabalho pressupõem alternativas ao trabalho subordinado típico, que não será superado tão facilmente. Nossa legislação já contempla contratação de trabalhadores autônomos - representantes comerciais. corretores de imóveis ou outras modalidades de corretagem, além de profissionais liberais - contadores, médicos, advogados, engenheiros, administradores, economistas, entre outros.

Mesmo assim, muitos desses trabalhadores conseguem provar subordinação e a Justiça do Trabalho garantu o registro em carteira e demais direitos próprios de empregado, supostamente sonegados. Se houve trabalho, presume-se subordinado; por que não inverter o ônus da prova, cabendo ao profissional liberal demonstrar a fraude no seu trabalho tido como autônomo?

Precisamos avançar. Nosso avanço limitou-se a contratar mão-de-obra por meios não-tradicionais. com abandono das empresas à própria sorte na busca de respostas e ajustes às novas exigências. ${ }^{\text {? }}$

Fntre tais desafios encontram-se as cooperativas de mão-de-obra e a parassubordinação.

\subsection{Cooperativas de mão-de-obra}

No Brasil, diversas motivações deram novo impulso às cooperativas de mão-de-obra, como tentativa de resposta aos desafios do novo cenário da sociedade pósindustrial. Dois modelos se apresentaram:

9 CHAAD, José Paulo 7eetano. As modalidades especiais de contrato de trabalho na CLT e a flexibilidade do mercado de trabalho brasileiro. In CHAAD, José Paulo Zeetano: CACCIAMALI. Maria Cristina. (Orgs.). Mercado de Trahalho no Brasil. Novas práticas trabalhistas, negociaçōes colctivas e direitos lundamentais no trabalho. São Paulo: L'Tr. 2003. p. 42. 
- Um, alternativo, em substituição ao regime da CLT e ao trabalho isolado do autônomo as verdadeiras cooperativas;

- Outro, fraudulento, expediente para burlar a legislação trabalhista pela sua rigidez, acusada de responsável pelo elevado custo da mão-de-obra. São as falsas cooperativas, meras intermediadoras de mão-de-obra.

Sabemos que grande parte do que hoje se denomina cooperativa de mão-deobra não passa de fraude. Resulta em parte da ganância de alguns em alcançar o lucro fácil e a qualquer preço. mas também do fracasso do nosso sistema de relações trabalhistas. que se esgotou com o fim de um modelo de produção, sem que tenhamos respostas para os desafios impostos pelas novas tecnologias da comunicação e informação.

Deixando de lado visões distorcidas, responsáveis pelas falsas cooperativas, uma série de fatores leva juristas e economistas, entre outros, a repensar o verdadeiro cooperativismo, para ocupar posição de destaque.

$\mathrm{O}$ brilho ostentado pelo cooperativismo, no passado, encoberto que foi pelo emprego estável, pujança da economia e intervenção do Fstado-Social, parece novamente envolver as cooperativas, com peso expressivo no conjunto da economia. com reais possibilidades de geração de empregos e formação profissional.

Entretanto, impõe-se legislação específica, não bastando introduzir um parágrafo no art. 442, da CLT, como já se fez, nem fazer adaptação das cooperativas de mão-de-obra com simples acréscimo de capítulo à Lei de cooperativas (Lei n. 5.764/71). A reforma é mais ampla, envolvendo o debate sobre o atual modelo protecionista da CLT e os novos desafios da denominada sociedade pós-industrial.

\subsection{Parassubordinação}

A dicotomia entre trabalho subordinado e trabalho autônomo é superada com a ligura da parassubordinação. Com origem na Itália, o avanço do teletrabalho e novas formas de trabalho em decorrência de novas tecnologias determinaram o surgimento de trabalhadores autônomos que utilizam a estrutura empresarial. $\mathrm{Na}$ parassubordinação, há autonomia e não-subordinação; verifica-se coordenação, no lugar do poder diretivo do empregador, embora haja continuidade do trabalho prestado. ${ }^{10}$ Por enquanto, não temos legislação a respeito: ou o trabalhador tem direito a tudo, porque é empregado, ou-não tem direito a nada, por ser autônomo.

10 Conf. SIllva, Otavio Pinto e. Subordinação, Autonomia e Parassubordinação nas Relaçòes de Trabalho. São Paulo: LTr. 2004. 
3. Novas formas de contratar trabalhadores

Não há espaço para a análise de todas as modalidades. "' Antes. deve-se abordar a flexibilização.

\subsection{Flexibilização}

Com as novas tecnologias da comunicação e informação, os conceitos de empregado e de subordinação passam por profunda revisão, determinando o avanço do trabalho autônomo, do trabalho à distância, do trabalho tımporário e a tempo parcial.

Denomina-se flexibilização as constantes revisões pelas quais passa o Direito do Trabalho, de preferência no plano da negociação coletiva, sem prejui\%o dos direitos fundamentais do trabalhador. Esse ajuste às novas realidades implica permanente oposição e conflito entre o princípio protccionista e a liberdade de gestão empresarial.

A flexibilização envolve um conflito maior, em face de concepções antagônicas sobre o papel do Direito na gestão da sociedade e a função do Direito do Trabalho na rıgulação das relações entre empregado e empregador. A primeira conccpção apresenta-se como intervencionista, de cunho protecionista; a outra, liberal, pregando maior liberdade na gestão da empresa, por meio de leis mínimas.

É possível concepção intermediária, segundo a qual cabe ao Estado papel promocional $^{12} \mathrm{e}$, ao Direito do Trabalho, de coordenação, conciliando os interesses entre o social e o econômico, ${ }^{13}$ seja promovendo valores fundamentais do trabalhador como pessoa humana, seja estimulando a eficácia e a competitividade da empresa no processo econômico.

Nesse cenário, a negociação coletiva desempenha papel fundamental na superação dos conflitos coletivos de natureza econômica ou de interesses, ou seja, na criação de norma para régular os interesses profissionais e econômicos e as condições de trabalho. Em outras palavras, há consenso generalizado no sentido de se dar maior preferência à negociação, cabendo ao Estado apenas impor um núcleo de valores nãosujeitos à derrogação das partes.

Contrariando a lógica do emprego formal com todos os direitos garantidos, as estatisticas demonstram que, enquanto os trabalhadores deste setor tiveram ganho real

\footnotetext{
1 Sobre essa questão, conferir, entre outros. MANNRICH, Nelson. A modernização do contrato de trabalho. São Paulo: LTr, 1998.

12 BOBBIO, Norberto. ('ontribucion a la Teoria del Derecho. Madri: Editorial Debate, 1990. p. 379 e ss.

13 NASCIMENTO, Amauri Mascaro. Iniciação ao Direito do Trabalho. São Paulo: LTr, 1997. p. 62 e ss. De acordo com o autor. o Direito do Trabalho desempenha uma função coordenadora.
} 
em torno de $11 \%$, com o Plano Real, os ganhos dos trabalhadores do setor informal ultrapassaram $24 \%$ e, dos autônomos, $40 \%$, o que justifica o contingente de $55 \%$ da força de trabalho no setor informal, quando em países mais desenvolvidos a média é $10 \%{ }^{14}$ Tais estatísticas acabam incentivando o descumprimento da lei e até comprometendo o Estado Democrático de Direito.

\subsection{Novas modalidades contratuais}

a. contratos atípicos

Fntendem-se como típicos os contratos de trabalho a tempo indeterminado. jomada integral, com um único empregador e junto de seu estabelecimento. Cedem lugar aos contratos atípicos, com preferência aos de prazo determinado e jornada parcial. Além disso, avança o teletrabalho e o trabalho temporário.

b. trabalho autônomo

Obscrva-se grande quantidade de falsos trabalhadores autônomos. São umpregados sem registro, obrigados a constituir sociedades empresariais ou integrar sociedades cooperativas. No Direito do Trabalho, prevalecem principios de proteção e o denominado contrato realidade, apesar das críticas. Em conseqüência, não basta celebrar contrato de prestação de serviços ou empreitada, se presentes os requisitos da relação de emprego, em especial a subordinação, enquanto não se reformar o atual ordenamento.

\section{c. terceirização}

Por meio da terceirização, as empresas concentram-se em sua atividade ou "foco" e, assim, tornam-se mais competitivas, pois reduzem custos com produção e aumentam a qualidade de seus produtos. Muitas vezes tais objetivos são escamoteados. ocorrendo apenas redução de custos com mão-de-obra.

Para o Direito do Trabalho, a terceirização, mais do que simples vantagem econômica ou melhora no processo de gestão da produção, restringe-sc à questão da responsabilidade, nos termos do Enunciado 331, do 'TST: Ou seja, sempre responde pelos direitos dos trabalhadores terceirizados o suu empregador. Excepcionalmente, o próprio tomador dos serviços será responsabilizado, seja na ocorrência de intermediação ilegal de mão-de-obra, scja pelo inadimplemento das obrigações trabalhistas por parte da empresa contratada.

14 PASTORE, José. A agonic do emprego. São Paulo: LTr, 1997. p. 86. 
O processo de terceirização apresınta-se comprometido, quando implantado para fraudar direitos dos trabalhadores. Aplica-se a teoria da nulidade dos atos jurídicos trabalhistas, nos termos do art. $9^{\circ}$ da CLT, prevalecendo o contrato realidade. Algumas empresas acabam contratando trabalhadores, disfarçados de autônomos. membros de cooperativas ou sem registro pura e simplesmente. Por vezes fica por isso mesmo. salvo se houver interferência dos poderes públicos, como fiscalização do Ministério do Trabalho ou intervenção do Ministério Público do Trabalho ou ajuizamento de reclamação trabalhista, hipóteses cada vez mais presentes.

Com base na construção doutrinária relativa aos verdadeiros fundamentos do Dircito do Trabalho e sua justificativa histórica de proteção, podem-se apontar três diretrizes extraídas da orientação jurispudencial e doutrinária, no sentido de se aferir se o processo de terceirização apresenta-se comprometido, gerando responsabilidade trabalhista do tomador dos serviços terceirizados.

\section{A forma como o poder é exercido}

Se o prestador de serviços nenhum poder excrce sobre seus empregados, não passa de empregador aparente, presumindo-se que sua atividade limita-se a fornecer mão-de-obra. Em contrapartida, o tomador dos serviços acaba assumindo o papcl de empregador real.

\section{A forma como o serviço é prestado}

O domínio de determinada tecnologia e prestação de um serviço ou tarefa precisa e definida contratualmente afasta a hipótese de mera intermediação de mão-deobra.

\section{Modo de remuneração}

Na terceirização, lida como correta, normalmente utiliza-se o sistıma de pagamento "à forfait" mediante preço previamente definido para uma tarefa especílica. Evidentemente, trata-se de mera presunção.

De qualquer forma. tomador e prestador de serviços devem apresentar-se como "sujeitos reais" no sentido de que o terceirizado corresponde a empregador real porque dirige a prestação dos serviços dos seus empregados, excrce uma atividade econômica c assume os riscos de sua atividade, ou verdadeiro autônomo - trabalha sem subordinação. 


\section{d. Trabalho temporário}

Regulado pela Lei n. 6.019/74, poderá a empresa utilizar-se de trabalhador temporário para substituição eventual de pessoal permanente ou para enfrentar acréscimo extraordinário de pessoal, em situações de pico de produção ou venda. O contrato tem duração máxima de três meses, com possibilidade de prorrogação por período idêntico, assegurados alguns direitos, inclusive o FGTS. Não há registro em carteira. Trata-se de intermediação legal de mão-de-obra e uma das mais utilizadas formas de trabalho atípico.

4. Novas alternativas para as empresas

Ultimamente. corr o intuito de dar suporte às empresas em meio à crise de todos conhecida, surgiram algumas alternativas à dispensa do empregado ou incentivos à sua contratação.

\subsection{Prazo determinado e geração de empregos}

Podem as empresas abandonar a tradicional restrição aos contratos de prazo determinado, como se infere da Lei n. 9.601/98, quando se tratar de aumento do quadro de pessoal.

\subsection{Suspensão contratual para qualificação do trabalhador}

Além disso, a empresa está autorizada a suspender o contrato de trabalho e submeter o empregado à qualif cação profissional, nos termos da Medida Provisória n. $2.164 / 2001$. Nesse período, entre dois e cinco meses, no lugar do salário, o empregado recebe seguro-desemprego, além de alguns outros benefícios, não podendo ser dispensado.

\subsection{Jornada parcial e banco de horas}

Outras alternativas foram introduzidas pcla Medida Provisória n. 2.164/2001, como o regime de tempo parcial, cuja duração não pode exceder de 25 horas semanais, bem como o banco de horas, com possibilidade de compensação anual da jornada. observada a média semanal de 44 horas e o limite diário de 10 horas, vedada a hora extra. 
4.4. Primeiro emprego e descontos em folha

Devem-se mencionar, ainda, a criação do programa nacional de estímulo ao primeiro emprego, regulado pela Lei n. 10.748/2003 e o sistema de desconto de prestações cm folha referente a pagamento de empréstimos, financiamentos operações de arrendamento, como se infere da Lei n. 10.820/2003.

\subsection{Consórcio de empregadorus}

O consórcio de empregadores rurais, regulado pela Lei n. 8.212/91, com as alterações introduzidas pela Lei n. 10.256/2001, foi implantado no meio rural. Aguarda-se sua extensão ao setor urbano, em especial na construção civil. Projetados para gerar, de pronto, mais 300 mil novos empregos, os resultados dos consórcios ainda são pífios.

Trata-se de forma de organização de pequenos produtores rurais, cujo objetivo é a exploração conjunta da atividade rural, mediante contratação direta dos empregados para trabalho exclusivo nas propricdades dos integrantes do consórcio. Foi implantada como alternativa ao sistema de cooperativa de mão-de-obra ou à contratação de bóia-fria.

Em outras palavras, o consórcio de empregadores rurais corresponde à união de produtores rurais, pessoas fisicas, resultante de um pacto de solidariedade com o intuito de contratar diretamente empregados rurais para trabalhar exclusivamente em suas propriedades, mediante registro em CTPS. Seu objetivo é racionalizar o custo com a contratação de mão-de-obra, respondendo todos solidariamente pelos encargos trabalhistas. Trata-se de associação de produtores rurais para contratação e gestão coletiva da mão-de-obra, sem partilha da propriedade, apenas do custo de sua exploração.

\subsection{Trabalho avulso}

Outra alternativa à contratação de trabalhadores corresponde ao trabalho avulso. A exemplo do que já ocorre na orla marítima, junto aos portos organizados. tal modalidade de trabalho poderia sur implantada na área urbana, como em grandes centros de abastecimento ou de exposições e feiras, bem como na área rural, como previsto pelo art.12, inc.VI, da Lei n. 8.212/91.

Critica-se a proposta de confiar ao sindicato a intermediação de mão-deobra por ser ilegal e compromuter sua função típica - defesa dos interesses profissionais. 


\section{Propostas de solução}

Além das novas modalidades de trabalho e outras alternativas contratuais, algumas medidas simples poderiam ser introduzidas, com inegáveis vantagens a todos.

Assim, tratamento diferenciado entre empresas e empregados. Quanto às empresas, propõe-se introduzir o que se denomina "mini CLT" ou "simples trabalhista", privilegiando a micro e pequena empresa, respeitados os direitos fundamentais do trabalhador. Quanto aos empregados, criar sistemas diferenciados de proteção, de sorte que altos dirigentes não tenham identica proteção dispensada a umpregados braçais.

Além disso, propõe-se rever a CLT, servindo de conteúdo mínimo dos contratos em geral, à falta de um contrato coletivo de trabalho. De qualquer forma, devem-sc observar as garantias constitucionais, cabendo à Constituição tixar os denominados "patamares mínimos" de proteção.

Para tanto, impõe-se prestigiar e estimular a neyociação coletiva, para recuperação do espaço hoje ocupado pelo Estado, próprio da autonomia dos grupos, o que implica substituir o atual modelo, onde há o predomínio da lei. Isso somente será concebivel se se implantar liberdade sindical, cujo protótipo é a Convenção n. 87, da OIT.

A maior reforma, no entanto, parece estar distante do debate: como introduzir no mercado formal de trabalho jovens, portadores de necessidades especiais e quantos já se encontram em idade madura, além dos milhares de trabalhadores na informalidade, com redução de encargos sociais e simplificações burocráticas, incluindose aí o próprio sistema de registro e ingresso no regime da seguridade social.

\section{Conclusões}

Não devemos nos colocar como críticos insatisfeitos, mas compreender a complexidade das mudanças e as novas realidades, pois todos somos agentes desse processo de transformações, cabendo ao jurista apresıntar um marco interpretativo do sentido global do itinerário do Direito do Trabalho, desde sua origem até os conturbados dias atuais e, assim, projetar suas novas atribuições.

O Direito do Trabalho deve apresentar-se tanto como instrumento protetor dos sujeitos mais débeis, como instrumento de convergência e integração entre as dimensões econômicas e sociais.

Impõe-se reformuiar o atual modclo, que não sc apresenta como racional. Para tanto, devemos superar a idéia cle que o Dircito do Trabalho apenas se ocupa do 
emprego típico, para abranger toda forma de trabalho. precário. eventual, autônomu ou parassubordinado.

Segundo Victor Hugo, a maior virtude do homem é ser razoável.

São Paulo. dezembro de 2005. 


\section{ANEXO I}

Componentes da empregabilidade (C'onforme "Career and Fmployability Skills - Contnt Standarts \& Benchmarks" elaborado pela Michigan Department of Education - 1998)

1. Aplicação dos conhecimentos acadêmicos: capacidade de utilizar a comunicação, conceitos científicos, sociais e matemáticos e aplicar tecnologias a fim de resolver problemas;

2. Planejamento de carreira: informações envolvendo mercado de trabalho / experiências profissionais;

3. Desenvolvimento e apresentação de informação: habilidade de combinar idćias e informações e apresentá-las por meio de simbolos, organogramas, gráficos ou imagens;

4. Resolução de problemas:estabelecimento de metas. identificação de recursos. verificação de alternativas e impactos, implementação de alternativas e avaliação de resultados;

5. Gerenciamento pessoal: desenvolvimento de habilidades como responsabilidade, auto-organização, auto-confiança, respeito e valores éticos;

6. Habilidade de organização: identificação, organização, planejamento u alocação de recursos de maneira eficiente e eficaz.

7. Trabalho em equipe: capacidade de cooperar com pessoas com diferentes "backgrounds" identificação de objetivos e valores do grupo. liderança. capacidade de ensinar outras pessoas e de contribuir com a equipe;

8. Técnicas de negociação: capacidade de defender uma posição e negociar interesses divergentes

9. Entendimento sistêmico: capacidade de entender, monitorar e aperfeiçoar sistemas complexos (sociais, técnicos e mecânicos) e de trabalhar com várias tecnologias:

10. Integração das próprias habilidades: capacidade de integrar as próprias habilidades a fim de estabelecer comportamentos que possibilitem obter, manter, avançar no emprego. 
ANEXO II

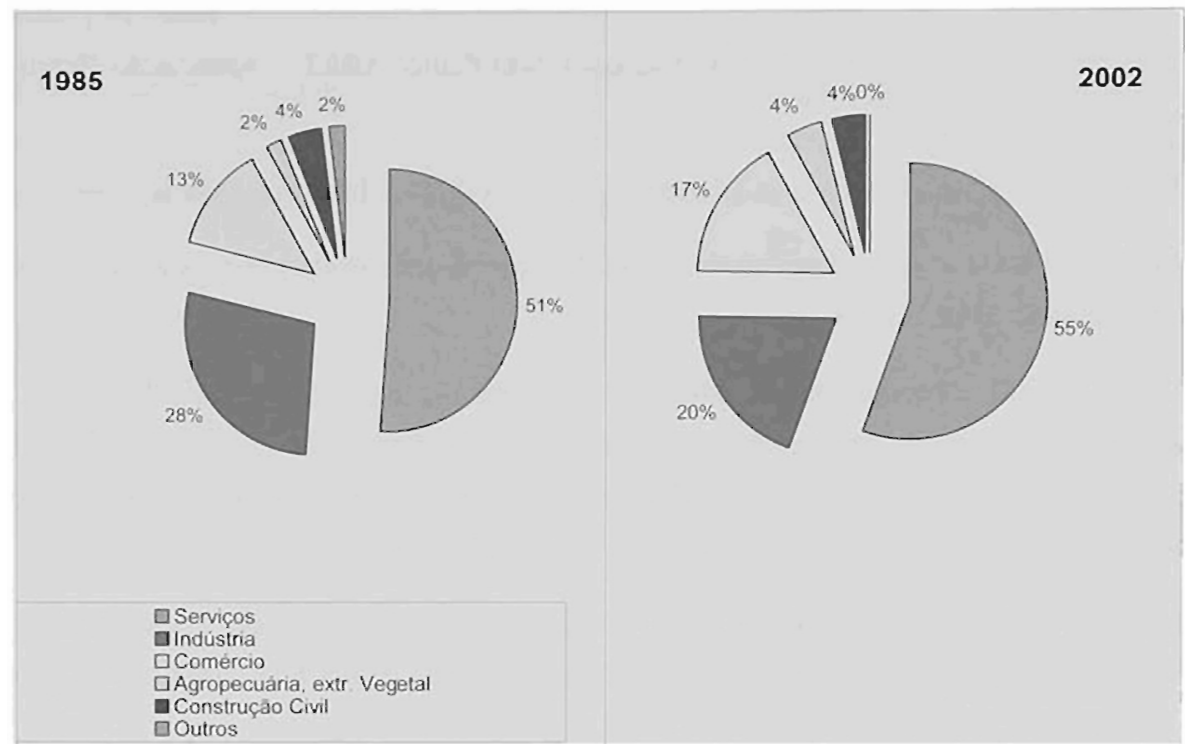

Escolaridade

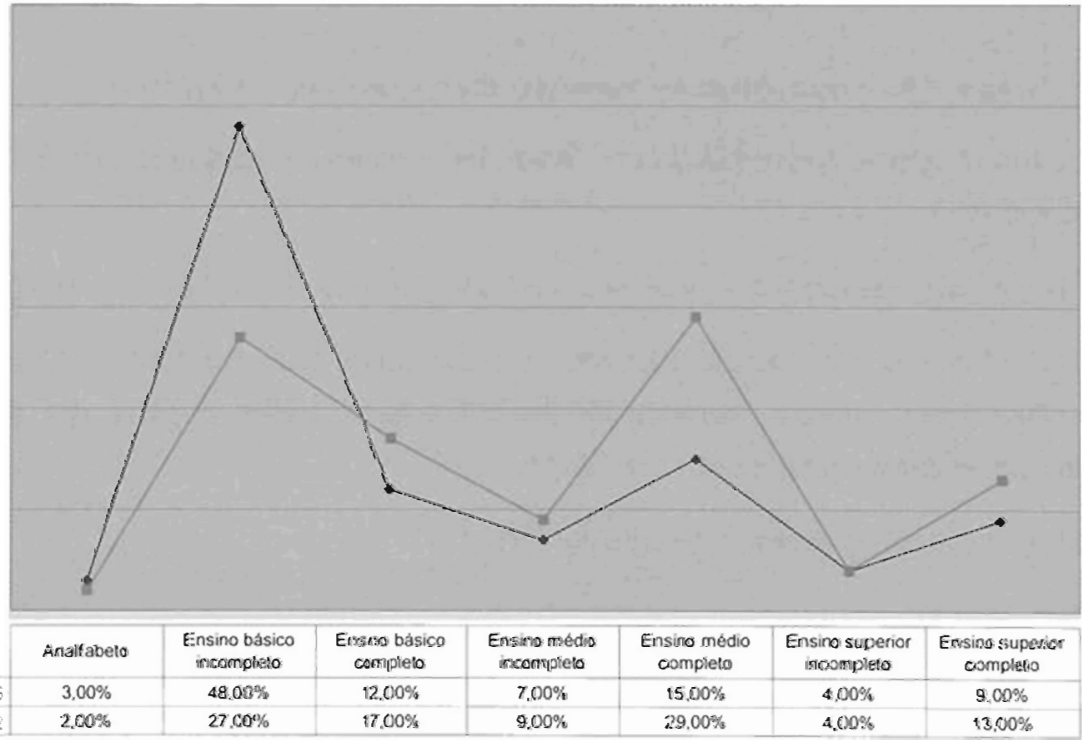




\section{Referências}

AZEREDO. Beatri . Politicus Püblicus de Emprego. São Paulo: ABET - Associação Brasileira de Estudos do Trabalho, 1998.

BOBBIO, Norberto. Contribucion a la Teoria del Derecho. Madri: Editorial Debate, 1990.

CARVALHO, Pedro Carlos de. Empregabilidade. A competência necessária para o sucesso no novo milênio. Campinas: Alínea, 2004.

CHAAD, José Paulo Zeetano. As modalidades especiais de contrato de trabalho na CLT e a flexibilidade do mercado de trabalho brasileiro. In: CHAAD. José Paulo Zeetano; CACCIAMALI, Maria Cristina. (Orgs.). Mercado de Trabalho no Brasil. Novas práticas trabalhistas, negociações coletivas e direitos fundamentais no trabalho. São Paulo: LTr, 2003.

CHAAD, José Paulo Zeetano: PICCHETTI, Paulo. (Orgs.). Mercado de Trabalho no Brasil. Padrões de comportamento e transformações institucionais. São Paulo: LTr, 2003.

JANUZZI, Paulo de Martino. Indicadores Sociais no Brasil. Conceitos. fontes de dados e aplicações. 2. ed. Campinas: Alínea, 2003.

KON, Anita; BANKO, Catalina; MELCHER, Dorothea; CACCIAMAI.I, Maria Cristina. (Coords.). Costos Sociales de lãs Reformas Neoliberales em América Latina. Caracas: Miguel Angul Garcia, 2000 .

MANNRICH, Nelson. Modernização do contrato de trabalho. São Paulo: LTr, 1998.

MINARELLI, José Augusto. Empregabilidade como tur trabalho e remuneração sempre. 24. ed. São Paulo: Gente, 1995.

NASCIMENTO, Amauri Mascaro. Iniciação uo Direito do Trubulho. São Paulo: LTr, 1997.

OIT - Oficina Internacional Del Trabajo. Panorama Laboral. Lima, 2003. In: WAJNMAN, Simone: MACHADO, Ana Flávia. (Org.). Mercado de Trabalho. Uma análise a partir das pesquisas domiciliares no Brasil. Belo Horizonte: UFMG. 2003.

PASTORE, Josè. A agonia do emprego. São Paulo: LTr. 1997.

POCHAMANN, Márcio. O emprego na globalização. A nova divisão internacional do trabalho ¿ os caminhos que o Brasil escolheu. São Paulo: Boitempo, 2001.

POCHAMANN, Márcio. (Org.). Recstruturaçio produriva. Purspectivas de desenvolvimento local com inclusão social. Petrópolis: Vozes, 2004. 
SILVA, Otavio Pinto e. Subordiną̧:ãu. Autonomia e Parassuhordinução nas Relações de Trabulho. São Paulo: LTr, 2004.

VIGORITA, Luciano Spagnuolo; CARINCI, Maria Teresa. (Urgs.). Quale futuro per il Diritto del Lavoro? La politica del (iovemo: dal libro bianco al disegno di legge delega sul mercato del lavoro. Atti della gionnata di studio. Milão: DOTT. A. Giuffrè. 2002. 